\title{
Membandingkan Metode SAW Dan MFEP Dalam Penentuan Jurusan di Tingkat SLTA
}

\author{
Rini Sovia ${ }^{1}$, Aulia Fitrul Hadi ${ }^{2}$ \\ ${ }^{1,2}$ Teknik Informatika, Ilmu Komputer,Universitas Putra Indonesia YPTK Padang \\ ${ }^{1}$ rini_sovia@ymail.com, ${ }^{2}$ fitrulhadi@gmail.com
}

\begin{abstract}
SMAN 10 Padang is one of the leading schools in the city of Padang State School which has two majors, namely Science (Science Knowledge) and Social Sciences (Social Sciences). A distinctive feature of this school is one of the international standard pilot schools (RSBI) by implementing bilingual and accelerating classes. On average students lack understanding in the selection of majors according to their abilities. Many people fail in the way they have found. To facilitate the determination of majors, a Decision Making System (SPK) is needed to find criteria. In SPK there are several methods in searching criteria, which are usually used by SAW with MFED. Based on the research carried out, by comparing the two methods, the data are grouped into three criteria, namely the value of the Natural Sciences National Examination, Psychology tests, and Interests. The results of this study show about MFEP method take a high accuration between SAW. An accuration of SAW have $38.3 \%$ and MFEP have $70.5 \%$.
\end{abstract}

Keywords: decision making system, majors, SAW, MFEP

\begin{abstract}
Abstrak
Sekolah Menengah Atas Negeri 10 Padang merupakan salah satu sekolah unggulan dikota Padang Sekolah menengah atas ini memiliki dua program jurusan yaitu IPA (IlmuPengetahuanAlam) dan IPS (Ilmu Pengetahun Sosial). Ciri khas dari sekolah menengah atas ini adalah salah satu sekolah rintisan sekolah bertaraf internasional (RSBI) dengan menerapkan kelas bilingual dan aselerasi. Kebanyakan para siswa kurang faham dalam pemilihan jurusan sesuai dengan kemampuan mereka. Akibatnya banyak para siswa baru yang gagal ditengah jalan ketika mereka sudah diterima dijurusan yang sudah didapatkan. Untuk memudahkan penentuan jurusan, ,maka diperlukan Sistem Pengambilan Keputusan ( SPK) untuk mencari kriteria. Pada SPK terdapat beberapa metode dalam pencarian kriteria, yang sering digunakan adalah metode $S A W$ dengan $M F E D$. Berdasarkan penelitian yang dilakukan, dengan membandingkan kedua metode tersebut, maka dikelompokkan data jurusan menjadi 3 kriteria,yakni nilai UN IPA, test Psikologi, dan Minat. Hasil dari penelitian ini menunjukkan bahwa metode $M F E P$ menghasilkan tingkat akurasi yang lebih tinggi dibandingkan metode $S A W$. Tingkat akurasi yang dihasilkan SAW yaitu sebesar $38.3 \%$ sedangkan MFEP sebesar $70.5 \%$.
\end{abstract}

Kata kunci: sistem pengambil keputusan, penjurusan, SAW, MFEP

(c) 2019 Jurnal RESTI

\section{Pendahuluan}

Di era globalisasi saat ini perkembangan teknologi informasi kian pesat, dengan perkembangannya yang kian pesat masyarakat dituntut untuk dapat mengikuti perkembangan tersebut agar dapat menguasai dan memanfaatkan teknologi informasi dalam menyelesaikan pekerjaan dan juga masalah yang dihadapi[1].

Sistem pendukung keputusan merupakan penggabungan sumber-sumber kecerdasan individu

DiterimaRedaksi : 11-09-2018 | SelesaiRevisi : 04-04-2019| |Diterbitkan Online : 30-04-2019 
dengan kemampuan komponen untuk memperbaiki kualitas keputusan. Sistem pendukung keputusan juga merupakan sistem informasi berbasis komputer untuk manajemen pengambilan keputusan yang menangani masalah-masalah semi terstruktur [2].

Dalam penelitian ini metode yang digunakan adalah yaitu Simple Addictive Weighting (SAW) dan Multifactor Evaluation Process(MFEP). Dengan membandingkan kedua metode dalam penelitian ini akan menghasilkan persentasi keakuratan dan mendukung keputusan yang dibutuhkan untuk menentukan jurusan yang cocok dengan siswa yang ada pada Sekolah Menengah Atas Negeri 10 Padang.

Hasil analisis dapat dilihat berdasarkan persentase keakuratan dari masing-masing metode yang digunakan. Metode Simple Addictive Weighting (SAW) membutuhkan beberapa kriteria dalam proses analisis. Pada metode Multifactor Evaluation Process(MFEP) membutuhkan nilai bobot dalam perhitungan analisis keakuratan.[3]

\subsection{Sistem Pengambilan Keputusan}

Sistem pendukung keputusan merupakan penggabungan sumber-sumber kecerdasan individu dengan kemampuan komponen untuk memperbaiki kualitas keputusan. Sistem pendukung keputusan juga merupakan sistem informasi berbasis komputer untuk manajemen pengambilan keputusan yang menangani masalah-masalah semi terstruktur [4]. Sistem Pendukung Keputusan (SPK) adalah salah satu cara mengorganisir informasi yang dimaksudkan untuk digunakan dalam membuat keputusan. Ada yang mendefinisikan bahwa sistem pendukung keputusan merupakan suatu pendekatan untuk mendukung pengambilan keputusan. Sistem pendukung keputusan menggunakan data, memberikan antarmuka pengguna yang mudah dandapat menggabungkan pemikiran pengambil keputusan[5].

\subsection{Metode Simple Additive Weight (SAW)}

Metode SAW merupakan metode Fuzzy MADM yang paling sederhana dan paling banyak digunakan. Metode ini juga metode yang paling mudah untuk diaplikasikan, karena mempunyai algoritma yang tidak terlalu rumit. Metode SAW sering juga dikenal istilah metode penjumlahan terbobot [6]. Konsep dasar metode SAW adalah mencari penjumlahan dari rating kinerja pada setiap alternatif pada semua atribut [6]. Langkah-langkah Penggunaan Metode SAW yaitu, menentukan kriteria-kriteria yang akan dijadikan acuan dalam pengambilan keputusan, Menentukan rating kecocokan setiap alternatif pada setiap kriteria, membuat matriks keputusan berdasarkan kriteria, kemudian melakukan normalisasi matriks berdasarkan persamaan yang disesuaikan dengan jenis atribut (atribut keuntungan ataupun atribut biaya) sehingga diperoleh matriks ternormalisasi, Hasil akhir diperoleh dari proses perankingan yaitu penjumlahan dari perkalian matriks ternormalisasi $\mathrm{R}$ dengan vektor bobot sehingga diperoleh nilai terbesar yang dipilih sebagai alternatif terbaik sebagai solusi[6].

\subsection{Metode Multifactor Evaluation Process ( MFEP)}

MFEP adalah metode kuantitatif yang menggunakan weighting system [7]. Dalam pengambilan keputusan multifactor, pengambil keputusan secara subyektif dan intuitif [7]. Keputusan yang berpengaruh secara strategis dianjurkan menggunakan sebuah pendekatan kuantitatif seperti MFEP[7].

Langkah-langkah pemecahan menggunakan metode MFEP adalah sebagai berikut [8]:

a. Dalam menentukan nilai bobot, memasukan nilai sebagai sample perhitungan dimana bobot faktor total pembobotan harus sama dengan 1 $\left(\sum\right.$ pembobotan $\left.=1\right)[8]$ atau disebut factor weight.

b. Mengisikan Nilai bobot faktor sesuai dengan beberapa alternatif yang dijadikan sebagai kandiditat

c. Proses perhitungan weight evaluation merupakan perhitungan antara factor weight dan factor evaluation dengan penjumlahan, dari hasil weight evaluation dapat menentukan hasil evaluasi

d. Dari hasil perhitungan tersebut diperoleh nilai weight evaluation

\section{Metode Penelitian}

\subsection{Subjek Penelitian}

Subjek yang akan dibahas pada penelitian ini adalah implementasi sistem pendukung keputusan dalam penentuan jurusan SMA Negri 10 Padang dengan menggunakan perbandingan metode Simple Addictive Weighting $(S A W)$ yang bertujuan untuk menganalisis berdasarkan kriteria yang ada dengan metode Multifactor Evaluation Process(MFEP) yang diimplementasikan dengan bahasa pemrograman PHP. Sistem yang dibuat ini diharapkan dapat memberikan keputusan yang tepat untuk guru dalam menentukan jurusan yang tepat untuk siswanya sesuai dengan kemampuan dan minat dari masing-masing siswanya tersebut.

\subsection{Diagram Proses Sistem Pendukung Keputusan}

Pada penelitian ini terdapat beberapa langkah yang dikerjakan mulai dari analisis data sampai dengan

mendapatkan hasil, diagram proses pada penelitian ini dapat dilihat pada Gambar 1.

\section{Hasil dan Pembahasan}

\subsection{Simple Addictive Weighting (SAW)}

\subsubsection{Menentukan Kriteria}


Dalam metode Simple Additive Weighting (SAW)

Tabel 1.Bobot Pendukung Faktor

terdapat kriteria yang dibutuhkan untuk proses perhitungan nantinya. Dalam kasus ini ada kriteria yang 1 akan digunakan untuk proses pengambilan keputusan 0.8 menentukan jurusan. Kriteria-kriteria tersebut adalah : 0.6 Nilai UN Bahasa Indonesia,Nilai UN Bahasa Inggris, 0.4 Nilai UN Matematika, Nilai UN IPA,Nilai Psikotes dan Minat .Rating kecocokan setiap alternative (penilaian) Nilai evaluasi setiap faktor bobot dikalikan evaluasi pada setiap kriteria yaitu : Sangat Baik (SB), Baik (B), Cukup (C), Kurang (K), dan Sangat Kurang (SK).

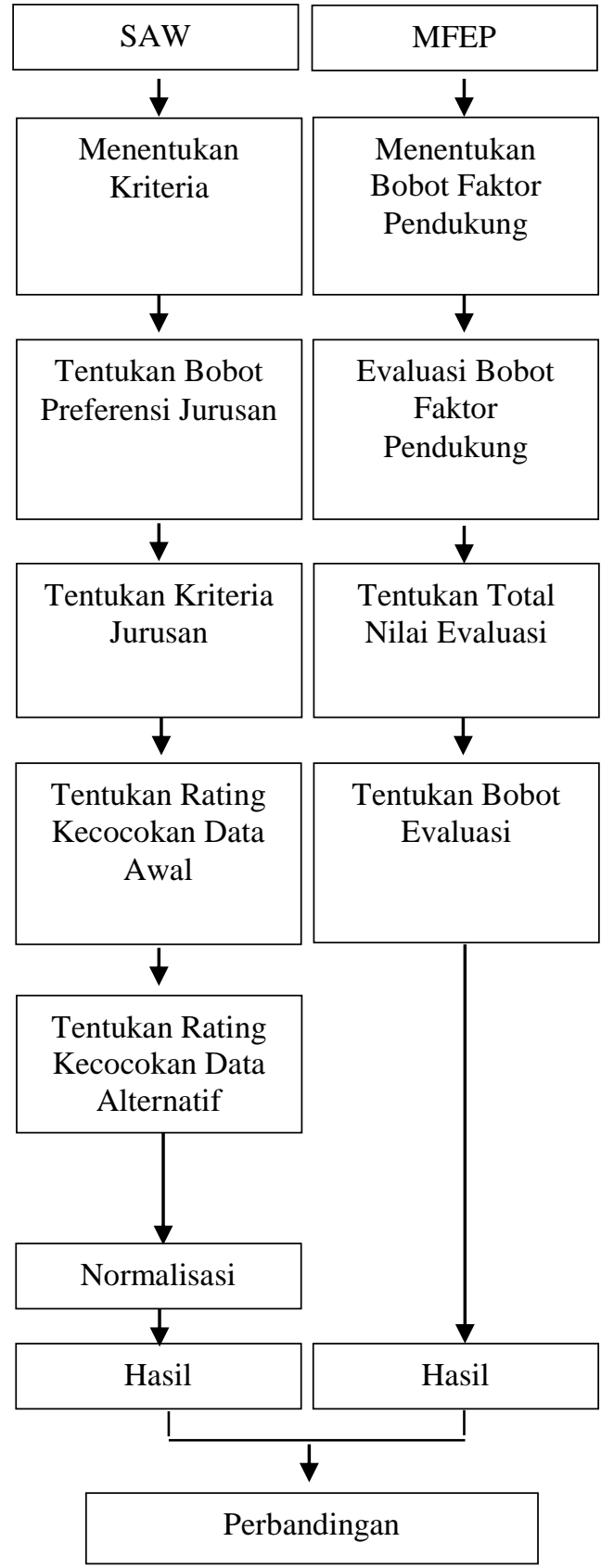

Gambar 1. Diagram Proses Sitem Pendukung Keputusan faktor, seperti dibawah ini :

Alternatif Siswa 1

$$
\begin{aligned}
& =(0.6 \times 80)+(0.3 \times 75)+ \\
& (0.1 \times 0) \\
& =48+22,5+0 \\
& =70,5 \\
& =(0.6 \times 60)+(0.3 \times 80)+ \\
& (0.1 \times 60) \\
& =36+24+6
\end{aligned}
$$

Alternatif Siswa 2

$=66$

\subsubsection{Menentukan Bobot Preferensi Jurusan}

Tahapan selanjutnya adalah menentukan bobot dari setiap nilai preferensi jurusan seperti yang terlihat pada tabel 2 .

\begin{tabular}{ll}
\multicolumn{2}{c}{ Tabel 2.Bobot Preferensi Jurusan } \\
\hline \multicolumn{1}{c}{ Kriteria } & $\begin{array}{c}\text { Jurusan } \\
\text { IPA }\end{array}$ \\
\hline Nilai UN Bahasa Indonesia & B \\
Nilai UN Bahasa Inggris & B \\
Nilai UN Matematika & SB \\
Nilai UN IPA & SB \\
Tes Psikologi & B \\
Minat & SB \\
\hline
\end{tabular}

\subsubsection{Menentukan Kriteria Jurusan}

Tahapan selanjutnya adalah menentukan Preferensi Bobot Tiap Kriteria Pada Tiap Jurusan seperti yang terlihat pada tabel 3.

\begin{tabular}{|c|c|c|c|c|c|c|}
\hline $\begin{array}{l}\text { Altern } \\
\text { atif }\end{array}$ & $\begin{array}{l}\text { Nilai } \\
\text { Un } \\
\text { Bahasa } \\
\text { Indones } \\
\text { ia }\end{array}$ & $\begin{array}{l}\text { Nilai } \\
\text { Un } \\
\text { Baha } \\
\text { sa } \\
\text { Inggr } \\
\text { is }\end{array}$ & $\begin{array}{l}\text { Nilai } \\
\text { UN } \\
\text { Mate } \\
\text { mati } \\
\text { ka }\end{array}$ & $\begin{array}{l}\text { Nil } \\
\text { ai } \\
\text { U } \\
\text { N } \\
\text { IP } \\
\text { A }\end{array}$ & $\begin{array}{l}\text { Nilai } \\
\text { Tes } \\
\text { Psikolo } \\
\text { gi }\end{array}$ & Minat \\
\hline A1 & 65 & 81 & 70 & 80 & 70 & SM \\
\hline A2 & 79 & 75 & 70 & 73 & 60 & M \\
\hline A3 & 60 & 72 & 75 & 70 & 60 & $\mathrm{C}$ \\
\hline
\end{tabular}

Tabel 3.Bobot Preferensi Pada Tiap Jurusan

\begin{tabular}{ll}
\hline Kriteria & $\begin{array}{l}\text { Jurusan } \\
\text { IPA }\end{array}$ \\
\hline C1 & 0,8 \\
C2 & 0,8 \\
C3 & 1 \\
C4 & 1 \\
C5 & 0,8 \\
C6 & 1 \\
\hline
\end{tabular}

\subsubsection{Tentukan Rating Kecocokan Awal}

Tahapan selanjutnya adalah menentukan Rating Kecocokan Awal seperti yang terlihat pada tabel 4.

Tabel 4.Rating Kecocokan Dari Data Awal 


\begin{tabular}{lllllll}
\hline A4 & 70 & 70 & 81 & 70 & 95 & TM \\
A5 & 76 & 75 & 75 & 81 & 80 & TM \\
\hline
\end{tabular}

\subsubsection{Tentukan Rating Kecocokan Data Alternatif}

Tahapan selanjutnya adalah menentukan Rating Kecocokan Data Alternatifseperti yang terlihat pada tabel 5 .

Tabel 5.Rating Kecocokan Dari Data Alternatif

\begin{tabular}{lllllll}
\hline Alternatif & C1 & C2 & C3 & C4 & C5 & C6 \\
\hline A1 & 2 & 4 & 2 & 3 & 1 & 5 \\
A2 & 3 & 3 & 2 & 3 & 1 & 4 \\
A3 & 1 & 3 & 3 & 2 & 1 & 3 \\
A4 & 2 & 2 & 4 & 2 & 3 & 1 \\
A5 & 3 & 3 & 3 & 4 & 2 & 1 \\
\hline
\end{tabular}

Nilai evaluasi setiap faktor bobot dikalikan evaluasi faktor, seperti dibawah ini :

Alternatif Siswa 1

$=(0.6 \times 80)+(0.3 \times 75)+$

$(0.1 \times 0)$

$=48+22,5+0$

$=70,5$

Alternatif Siswa 2

$$
=70,5
$$$$
\begin{aligned}
& =(0.6 \times 60 \\
& (0.1 \times 60) \\
& =36+24+(4)
\end{aligned}
$$$$
=36+24+6
$$$$
=66
$$

Alternatif Siswa 3

$$
\begin{aligned}
& =(0.6 \times 70)+(0.3 \times 85)+ \\
& (0.1 \times 0) \\
& =42+25,5+0 \\
& =67,5
\end{aligned}
$$

\subsubsection{Normalisasi}

Setelah mendapat kan nilai dari tabel rating kecocokan dari alternatif maka kita dapat menentukan matriks keputusan (matriks X).

$\mathrm{X}=\left\{\begin{array}{cccccc}2 & 4 & 2 & 3 & 1 & 5 \\ 3 & 3 & 2 & 3 & 1 & 4 \\ 1 & 3 & 3 & 2 & 1 & 3 \\ 2 & 2 & 4 & 2 & 3 & 1 \\ 3 & 3 & 3 & 4 & 2 & 1\end{array}\right\}$

Langkah selanjutnya dalam metode Simple Additive Weighting $(S A W)$ adalah melakukan normalisasi

\begin{tabular}{|c|c|c|}
\hline $\mathrm{R} 11=$ & $\frac{2}{\operatorname{Maks}(2,3,1,2,3)}$ & $=\frac{2}{3}=0,66$ \\
\hline \multirow[t]{2}{*}{$\mathrm{R} 12=$} & 3 & $=3=1$ \\
\hline & Maks $(2,3,1,2,3)$ & 3 \\
\hline $\mathrm{R} 21=$ & $\frac{4}{\operatorname{Maks}(4,3,3,2,3)}$ & $=\frac{4}{4}=1$ \\
\hline \multirow[t]{2}{*}{$\mathrm{R} 22=$} & 3 & $=3=0,7$. \\
\hline & Maks $(4,3,3,2,3)$ & 4 \\
\hline
\end{tabular}
matriks keputusan $\mathrm{X}$ dengan cara menghitung nilai rating kinerja ternormalisasi (Rij) dari alternatif (Ai) pada kriteria (Cj)[8]. Sebagai contoh melakukan perhitungan untuk R11, R12, R21, dan R22.

Setelah melakukan perhitungan Vi maka didapatkan lah hasil akhir dari penentuan jurusan siswa. Setiap siswa yang memiliki nilai total diatas dari $>3,00$ maka status jurusan IPA dan siswa dengan nilai total $<3.00$ status jurusan IPS.

Tabel 7. Hasil perhitungan Nilai V

\begin{tabular}{cc}
\hline Alternatif & Nilai Total \\
\hline V1 & 3,83 \\
V2 & 3,71 \\
V3 & 2,97 \\
V4 & 3,42 \\
V5 & 3,87 \\
\hline
\end{tabular}

Setelah didapatkan nilai ternormalisasi maka dilanjutkan dengan menghitung nilai preferensi (Vi). Nilai $\mathrm{V}$ diperoleh dari penjumlahan dari perkalian elemen baris matrik ternormalisasi (R) dengan bobot preferensi (W) yang bersesuaian elemen kolom matrik (W)[8]. Nilai total Vi untuk jurusan dapatdihitung +dengan nilai perkalian pada tabel 4.11 dengan nilai bobot $\mathrm{W}$ jurusan IPA $=\left\{\begin{array}{llllll}0,8 & 0,8 & 1 & 1 & 0,8 & 1\end{array}\right\}$ dengan matriks R. Sebagai contoh menghitung nilai V1. V1 = $(0,8)(0,66)+(0,8)(1)+(1)(0,5)+(1)(0,75)+(0,8)$ $+(0,33)+(1)(1)=0,52+0,8+0,5+0,75+0,26+1$ $=3,83$

\begin{tabular}{ccc}
\multicolumn{3}{c}{ Tabel 8. Hasil Keputusan } \\
\hline Alternatif & Nilai Total & Status \\
\hline A1 & 3,83 & IPA \\
A2 & 3,71 & IPA \\
A3 & 2,97 & IPS \\
A4 & 3,42 & IPA \\
A5 & 3,87 & IPA \\
\hline
\end{tabular}

3.2 Multifactor Evaluatian Process (MFEP)

Menentukan faktor yang dijadikan acuan dalam pengambilan keputusan beserta bobotnya

Tabel 9. Bobot Faktor Pendukung

\begin{tabular}{lll}
\hline No & Nama Faktor Pendukung & Bobot \\
\hline 1 & Nilai UN IPA SMP & $60 \%$ \\
2 & Tes Psikologi & $30 \%$ \\
3 & Minat & $10 \%$ \\
\hline
\end{tabular}

Setelah dilakukan pembobotan, setiap siswa yang akan melakukan penjurusan akan dievaluasi dan diberikan nilai bobot untuk masing-masing setiap kriteria seperti tabel 10. 


\begin{tabular}{ccccc}
\multicolumn{5}{c}{ Tabel 10 .Proses Perhitungan } \\
\hline Faktor & Siswa 1 & Siswa 2 & Siswa 3 & $\mathrm{Ke}-\mathrm{n}$ \\
\hline Nilai UN IPA & 80 & 60 & 70 & - \\
Tes Psikologi & 75 & 80 & 85 & - \\
Minat & 0 & 60 & 0 & - \\
\hline
\end{tabular}

$=42+25,5+0$

Dengan adanya informasi diatas, didapat total nilai evaluasi untuk setiap alternatif. Setiap siswa memiliki nilai evaluasi bagi ketiga faktor yang menjadi pertimbangannya, untuk mendapat nilai total evaluasi setiap siswa yang ingin memilih jurusan dengan cara perhitungan sebagai berikut :

Perhitungan nilai bobot evaluasi

Nbe $=$ Nbf $x$ Nef

Keterangan :

Nbe $\rightarrow$ Total Nilai Evaluasi

$\mathrm{Nbf} \rightarrow$ Nilai Bobot Evaluasi

Nef $\rightarrow$ Nilai evaluation Faktor

Perhitungan total nilai evaluasi

Tne $=$ Nbe $1+\mathrm{Nbe} 2+\mathrm{Nbe} 3 \ldots$.

Keterangan :

Tne $\rightarrow$ Total Nilai Evaluasi

Nbe $\rightarrow$ Total Nilai Evaluasi

Tabel 11. Evaluasi Untuk Siswa 1

\begin{tabular}{lllll}
\hline Faktor & $\begin{array}{l}\text { Bobot } \\
\text { Faktor }\end{array}$ & & Evaluasi faktor & $\begin{array}{l}\text { Bobot } \\
\text { Evaluasi }\end{array}$ \\
\hline Nilai UN IPA & 0.6 & $\mathrm{X}$ & 80 & 48 \\
Tes Psikologi & 0.3 & $\mathrm{X}$ & 60 & 22,5 \\
Minat & 0.1 & $\mathrm{X}$ & 0 & 0 \\
Total & 1 & & & 70,5 \\
\hline
\end{tabular}

Tabel 12. Evaluasi Untuk Siswa 2

\begin{tabular}{|c|c|c|c|c|}
\hline Faktor & $\begin{array}{l}\text { Bobot } \\
\text { Faktor }\end{array}$ & & Evaluasi faktor & $\begin{array}{l}\text { Bobot } \\
\text { Evaluasi }\end{array}$ \\
\hline Nilai UN IPA & 0.6 & $\mathrm{X}$ & 60 & 36 \\
\hline Tes Psikologi & 0.3 & $X$ & 80 & 24 \\
\hline Minat & 0.1 & $\mathrm{X}$ & 60 & 6 \\
\hline Total & 1 & & & 66 \\
\hline
\end{tabular}

Tabel 13. Evaluasi Untuk Siswa 3

\begin{tabular}{lllll}
\hline Faktor & $\begin{array}{l}\text { Bobot } \\
\text { Faktor }\end{array}$ & & Evaluasi faktor & $\begin{array}{l}\text { Bobot } \\
\text { Evaluasi }\end{array}$ \\
\hline Nilai UN IPA & 0.6 & $\mathrm{X}$ & 70 & 42 \\
Tes Psikologi & 0.3 & $\mathrm{X}$ & 85 & 25,5 \\
Minat & 0.1 & $\mathrm{X}$ & 0 & 0 \\
Total & 1 & & & 67,5 \\
\hline
\end{tabular}

Langkah perhitungannya :

Nilai evaluasi setiap faktor bobot dikalikan evaluasi faktor, seperti dibawah ini :

Alternatif Siswa 1

$(0.1 \times 0)$

$=48+22,5+0$

$=70,5$

Alternatif Siswa 2

$(0.1 \times 60)$

$=36+24+6$

$=66$

Alternatif Siswa $3=(0.6 \times 70)+(0.3 \times 85)+(0.1 \times 0)$
Tabel 14. Hasil Total Bobot Evaluasi

\begin{tabular}{lll}
\hline No & Nama & Total Bobot Evaluasi \\
\hline 1 & Siswa 1 & 70,5 \\
2 & Siswa 2 & 66 \\
3 & Siswa 3 & 67,5 \\
\hline
\end{tabular}

Dari proses perhitungan diatas setelah didapatkan total bobot evaluasi maka akan ditentukan status jurusan berdasarkan nilai total bobot evaluasi yang telah didapat, status jurusan ditentukan berdasarkan total nilai yang dia dapat, apabila total nilai diatas 70 maka status jurusan IPA jika di bawah 70 maka status jurusan IPS.

Tabel 15. Hasil Keputusan

\begin{tabular}{llll}
\hline No & Nama & Total Bobot Evaluasi & Status \\
\hline 1 & Siswa 1 & 70,5 & IPA \\
2 & Siswa 2 & 66 & IPS \\
3 & Siswa 3 & 67,5 & IPS \\
\hline
\end{tabular}

Setelah didapatkan nilai ternormalisasi maka dilanjutkan dengan menghitung nilai preferensi (Vi). Nilai $\mathrm{V}$ diperoleh dari penjumlahan dari perkalian elemen baris matrik ternormalisasi (R) dengan bobot preferensi $(\mathrm{W})$ yang bersesuaian elemen kolom matrik (W).

Nilai total Vi untuk jurusan dapatdihitung dengan nilai perkalian pada tabel 4.11 dengan nilai bobot $\mathrm{W}$ jurusan IPA $=\left\{\begin{array}{llllll}0,8 & 0,8 & 1 & 1 & 0,8 & 1\end{array}\right\}$ dengan matriks R. Sebagai contoh menghitung nilai V1.

$\mathrm{V} 1=(0,8)(0,66)+(0,8)(1)+(1)(0,5)+(1)(0,75)+$ $(0,8)(0,33)+(1)(1)$

$$
\begin{aligned}
& =0,52+0,8+0,5+0,75+0,26+1 \\
& =3,83
\end{aligned}
$$

Tabel 12. Hasil perhitungan Nilai V

\begin{tabular}{cc}
\hline Alternatif & $\begin{array}{c}\text { Nilai } \\
\text { Total }\end{array}$ \\
\hline$V 1$ & 38.3 \\
\hline$V 2$ & 37.1 \\
\hline$V 3$ & 29.7 \\
\hline$V 4$ & 34.2 \\
\hline$V 5$ & 38.7 \\
\hline
\end{tabular}

Setelah melakukan perhitungan Vi maka didapatkan lah hasil akhir dari penentuan jurusan siswa. Setiap siswa yang memiliki nilai total diatas dari $>3,00$ maka status jurusan IPA dan siswa dengan nilai total $<3.00$ status jurusan IPS.

Tabel 13. Hasil Keputusan SAW

\begin{tabular}{ccc}
\hline Alternatif & $\begin{array}{c}\text { Nilai } \\
\text { Total }\end{array}$ & Status \\
\hline A1 & 38.3 & IPA \\
A2 & 37.1 & IPA \\
A3 & 29.7 & IPS \\
A4 & 34.2 & IPA \\
A5 & 38.7 & IPA \\
\hline
\end{tabular}


setelah proses analisis dan perbandingan dilakukan didapatkan bahwa Simple Addictive Weighting (SAW) dengan mengambil salah satu sample data ternyata memiliki tingkat keakuratan sebesar $38.3 \%$ dan Multifactor Evaluation Process(MFEP) sebesar 70.5 $\%$. SAW memiliki perhitungan yang lebih baik karena adanya proses normalisasi sedangkan MFEP tidak ada terjadi proses normalisasi.terlihat dari perbandingan 2 siswa berikut.

Tabel 14. MFEP

\begin{tabular}{cccc}
\hline No & Nama & $\begin{array}{c}\text { Total Bobot } \\
\text { Evaluasi }\end{array}$ & Status \\
\hline 1 & Siswa 1 & 70,5 & IPA \\
2 & Siswa 2 & 66 & IPS \\
\hline \multicolumn{3}{c}{ Tabel 15. SAW } \\
\multicolumn{5}{c}{ Nilai Total } & Status \\
\hline Alternatif & IPA \\
Siswa 1 & 38.3 & IPA \\
Siswa 2 & 37.1 & C
\end{tabular}

Tahapan analisis data merupakan tahapan yang penting dalam pengembangan sebuah sistem, karena pada tahap ini terdapat kegiatan evaluasi kinerja, identifikasi masalah yang ada, rancangan sistem dan langkah-langkah yang dibutuhkan untuk perancangan yang diinginkan sampai pada analisis yang diharapkan.

Penelitian ini menggunakan bahasa program PHP sebagai alat bantu untuk pengambilan keputusan. Perancangan pada analisis data ini terdiri dari analisis data faktor beserta bobotnya.

Gambar 2 - 5 merupakan hasil analisis dan penerapan.

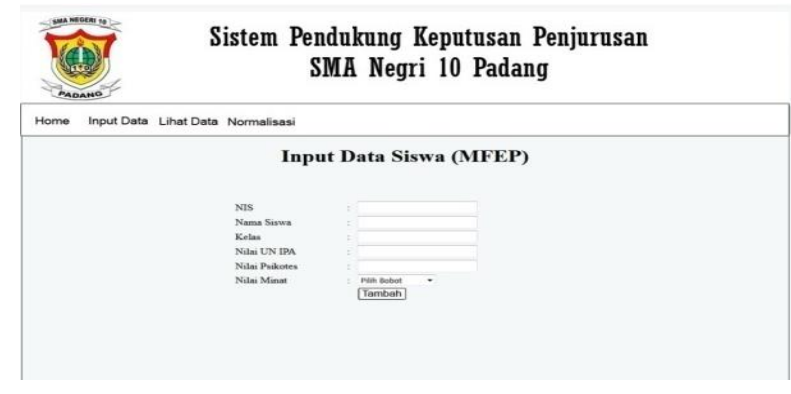

Gambar 2. Analisis Menggunakan MFEP

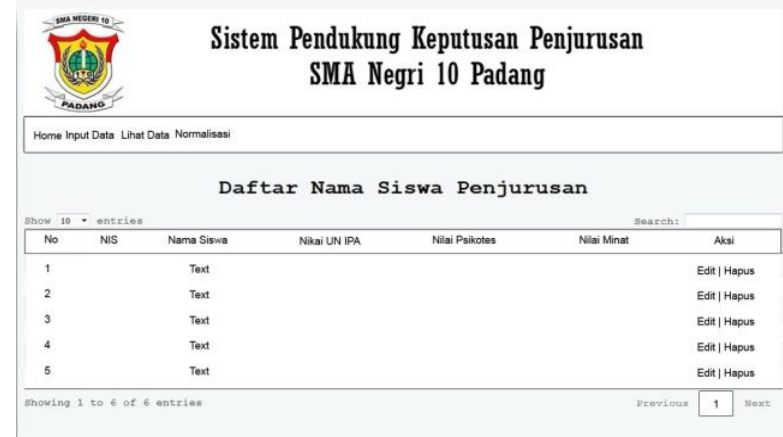

Gambar 3. Hasil Menggunakan SAW

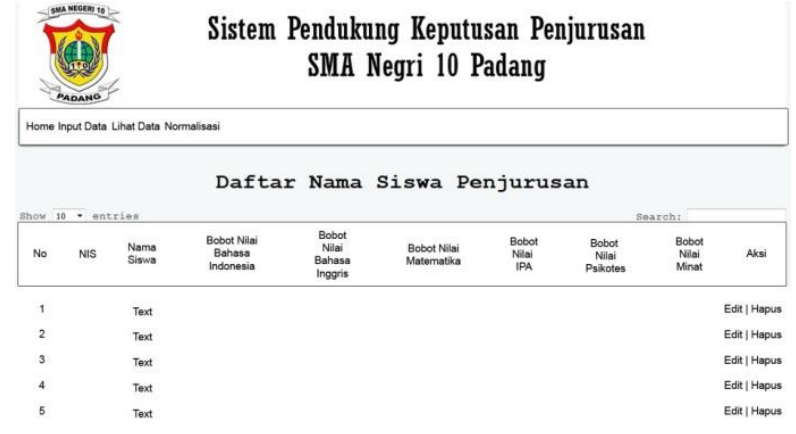

Gambar 4. Hasil Menggunakan MFEP

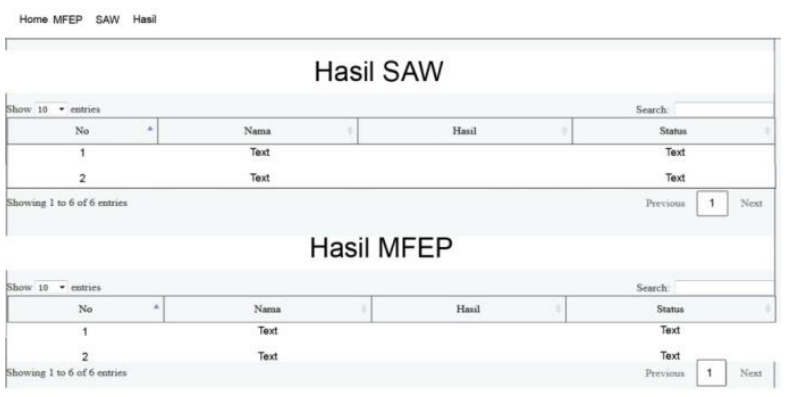

Gambar 5. Perbandingan Hasil Analisis

\section{Kesimpulan}

Dari hasil analisis yang telah dilakukan, maka dapat di tarik kesimpulan sebagai berikut:

Analisis ini membuktikan bahwa $S A W$ memiliki tingkat akurasi lebih baik dari MFEP. Di buktikan dari adanya tahap normalisai pada $S A W$ dan tidak terdapat pada MFEP. Hasil keputusan dari dua metode ini ditentukan berdasarkan kriteria yang dibutuhkan oleh masingmasing metode. Ternyata kriteria yang dibutuhkan oleh $S A W$ lebih banyak dibandingkan MFEP. Terbukti bahwa hasil keputusan yang dihasilkan oleh $S A W$ lebih baik.Analisis menggunakan Simple Addictive Weighting (SAW) dengan menggunakan kriteria nilai UN Bahasa Indonesia, Bahasa Inggris, Matematika, IPA, Test Psikologi menghasilkan tingkat akurasi sebesar $38.3 \%$, sedangkan MFEP dengan bobot pendukung yaitu nilai UN IPA, Test Psikologi dan Minat menghasilkan tingkat akurasi sebesar $70.5 \%$.

\section{Ucapan Terimakasih}

Terima kasih kami ucapkan kepada Universitas Putra Indonesia YPTK Padang yang telah mendanai penuh penelitian ini.

\section{Daftar Rujukan}

[1]. Iqbal Maulana, Yana. "Perancangan Perangkat Lunak Sistem Informasi Pendataan Guru Dan Sekolah (SINDARU) Pada dinas Pendidikan Kota Tangerang Selatan". Yogyakarta:Jurnal Pilar Nusantara Mandiri (2017). 
[2]. Kendall, Kennet E., dan Kendall, Jullie E., 2010. Analisis dan [6]. Attributte Decision Making (Fuzzy MADM). Graha Ilmu, Perancangan Sistem Edisi ke-5 (Versi Bahasa Indonesia). Indeks, Jakarta.

[3]. Deni, Widayanti, Sudana, Oka, dan Sasmita, Arya, 2013, Analysis and Implementation

[4]. Fuzzy Multi-Attribute Decision Making SAW Method for Selection of High Achieving.

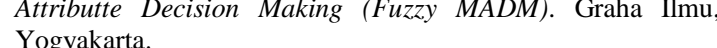

[7]. Suparth, I Kade Dwi Grandika., Dewi, I Gusti Ayu Putu Eka Purnama, 2014, SistemPendukung Keputusan Penentuan Jurusan Pada SMK Kertha Wisata Dendapasar menggunakan Fuzzy SAW, Jurnal Nasional Pendidikan Teknik Informatika (JANAPATI)Volume 3, Nomor 2.

[5]. Students in Faculty Level. IJCSI International Journal of [8]. Computer Science Issues, No 2,Vol. 10, Issue Kusumadewi., Sri, Hartati., Sri, Harjoko., Agus, dan Wardoyo., Retantyo, Prayoko, MhbRiki, 2013, Sistem Pendukung Keputusan Penentuan Jurusan Pada SekolahMenengah Atas SMA Setia Budi Abadi Perbaungan Dengan Menggunakan Metode Simple Additive Weighting (SAW), Jurnal Ilmiah Pelita Informatika Budi Darma Vol. V, No.2. 